PUBLIK: Jurnal Manajemen Sumber Daya Manusia, Adminsitrasi dan Pelayanan Publik Sekolah Tinggi Ilmu Administrasi Bina Taruna Gorontalo Volume VII Nomor 12020

\title{
PENGARUH BUDAYA ORGANISASI TERHADAP KINERJA PEGAWAI DI KANTOR CAMAT DUNGINGI KOTA GORONTALO
}

\author{
Swastiani Dunggio \\ Universitas Ichsan Gorontalo \\ swastianidunggio@yahoo.co.id
}

\begin{abstract}
ABSTRAK
Setiap organisasi memiliki ciri khas yang membedakannya dengan organisasi lain, ciri khas ini menjadi identitas bagi organisasi. Budaya organisasi dapat membantu kinerja pegawai, karena menciptakan suatu tingkat motivasi yang besar bagi pegawai untuk memberikan kemampuan terbaiknya dalam memanfaatkan kesempatan yang diberikan oleh organisasinya. Tujuan dari penelitian ini adalah untuk mengetahui fakta, data dan hal-hal yang berkaitan dengan permasalahan variabel budaya organisasi dan kinerja pegawai. Peneliti menggunakan jenis penelitian survey dengan pendekatan kuantitatif, yaitu penelitian yang menggunakan kata-kata atau kalimat dengan beserta angka-angka dengan memakai sampel dan menggunakan kuesioner sebagai alat pengumpulan data pokok. Adapun dalam pengumpulan data dilakukan dengan metode Observasi, Kuesioner. Hasil penelitian menunjukkan bahwa, Pengaruh budaya konstruktif $\left(\mathrm{X}_{1}\right)$ terhadap kinerja pegawai (Y) sebesar 0,445 atau 44,5\% dengan nilai signifikansi sebesar 0,007. Menunjukkan bahwa semakin baiknya budaya konstruktif akan berdampak pada meningkatnya kinerja pegawai. Pengaruh budaya pasif-defensif $\left(\mathrm{X}_{2}\right)$ terhadap kinerja pegawai $(\mathrm{Y})$ sebesar 0,332 atau $33,2 \%$ dengan nilai signifikansi sebesar 0,017. Menunjukkan bahwa semakin baiknya budaya pasif-defensif akan berdampak pada meningkatnya kinerja pegawai. Pengaruh budaya Agresif-defensif $\left(\mathrm{X}_{3}\right)$ terhadap kinerja pegawai $(\mathrm{Y})$ sebesar 0,568 atau 56,8\% dengan nilai signifikansi sebesar 0,003. Menunjukkan bahwa semakin baiknya budaya agresif-defensif akan berdampak pada meningkatnya kinerja pegawai. Simpulannya, terdapat pengaruh budaya organisasi secara simultan dan parsial terhadap kinerja pegawai pada Kantor Camat Dungingi Kota Gorontalo
\end{abstract}

Kata Kunci: Budaya Organisasi; Kinerja Pegawai

\begin{abstract}
Every organization has a characteristic that distinguishes it from other organizations, this characteristic becomes the identity of the organization. Organizational culture can help employee performance because it creates a large level of motivation for employees to provide the best ability to take advantage of the opportunities provided by the organization. The purpose of this study is to find out facts, data, and matters relating to organizational culture variables and employee performance. Researchers used a type of survey research with a quantitative approach, namely research that uses words or sentences along with
\end{abstract}


PUBLIK: Jurnal Manajemen Sumber Daya Manusia, Adminsitrasi dan Pelayanan Publik Sekolah Tinggi Ilmu Administrasi Bina Taruna Gorontalo Volume VII Nomor 12020

numbers by using samples and using questionnaires as a primary data collection tool. The data collection is done by the method of observation, questionnaires. The results showed that, the effect of constructive culture (X1) on employee performance (Y) of 0.445 or $44.5 \%$ with a significance value of 0.007. Demonstrates that a better constructive culture will have an impact on improving employee performance. The influence of passive-defensive culture (X2) on employee performance (Y) of 0.332 or $33.2 \%$ with a significance value of 0.017. Show that the better passive-defensive culture will have an impact on improving employee performance. The influence of Aggressive-defensive culture (X3) on employee performance (Y) of 0.568 or $56.8 \%$ with a significance value of 0.003 . Show that the better the aggressive-defensive culture will have an impact on improving employee performance. In conclusion, there is an influence of organizational culture simultaneously and partially on employee performance at the Gorontalo District Dungingi Office.

Keywords: Organizational Culture; Employee Performance

\section{PENDAHULUAN}

Manusia sebagai makhluk sosial pada dasarnya mempunyai sifat untuk bersosialisasi, bekerja sama, dan membutuhkan keberadaan manusia lainnya. Untuk itu keberadaan sebuah organisasi sangat diperlukan sebagai suatu wadah yang dapat menghimpun atau mempermudah manusia dalam bersosialisasi dan bekerja sama.

Organisasi merupakan suatu sarana yang beranggotakan orang-orang yang bekerja sama untuk mencapai tujuan bersama. Keberhasilan suatu organisasi sangat erat kaitannya dengan kualitas kinerja para anggotanya, sehingga organisasi dituntut untuk selalu mengembangkan dan meningkatan kinerja dari para anggotanya. Kinerja berarti hasil kerja yang dapat ditampilkan atau penampilan kerja seseorang pegawai. Dengan demikian, kinerja seorang karyawan dapat diukur dari hasil kerja, hasil tugas, atau hasil kegiatan dalam kurun waktu tertentu (Notoatmodjo, 2009:124).
Kinerja pegawai yang tinggi akan mendukung produktivitas organisasi, sehingga sudah seharusnya pimpinan organisasi senantiasa memperhatikan peningkatan kinerja anggotanya demi kemajuan organisasi. Peningkatan kinerja para anggota juga erat kaitannya dengan cara bagaimana organisasi mengembangkan budaya organisasi yang ada.

Setiap organisasi memiliki ciri khas yang membedakannya dengan organisasi lain, ciri khas ini menjadi identitas bagi organisasi. Ciri khas inilah yang dinamakan budaya organisasi. Budaya organisasi mengacu pada hubungan yang unik dari norma-norma, nilai-nilai, kepercayaan dan cara berperilaku yang menjadi ciri bagaimana kelompok dan individu dalam menyelesaikan sesuatu. Budaya organisasi mengandung nilainilai yang harus dipahami, dijiwai, dan dipraktikkan bersama oleh semua individu/kelompok yang terlibat di dalamnya. 
PUBLIK: Jurnal Manajemen Sumber Daya Manusia, Adminsitrasi dan Pelayanan Publik Sekolah Tinggi Ilmu Administrasi Bina Taruna Gorontalo Volume VII Nomor 12020

Budaya organisasi juga akan memiliki dampak pada efisiensi dan efektivitas organisasi dan pemberdayaan pegawai (employee empowerment) di suatu organisasi. Budaya organisasi dapat membantu kinerja pegawai, karena menciptakan suatu tingkat motivasi yang besar bagi pegawai untuk memberikan kemampuan terbaiknya dalam memanfaatkan kesempatan yang diberikan oleh organisasinya. Budaya yang kuat merupakan kunci kesuksesan sebuah organisasi. Menurut Ndraha, (2004:68) budaya yang kuat mempunyai 3 ciri, yaitu: Kejelasan nilai-nilai dan keyakinan (Clarity of Ordering); Penyebaran nilai-nilai dan keyakinan (Extent Of Ordering); Kekokohan nilainilai inti dan keyakinan (Core Values Being Intensely Held)

Dalam organisasi publik/pemerintah di Indonesia, kinerja organisasi publik merupakan hal yang sangat penting guna mewujudkan tata kelola pemerintahan yang baik (Good Governance) dan pemerintahan yang bersih (Clean Governance), serta mendukung tugas-tugas pemerintahan untuk memberikan pelayanan yang terbaik kepada masyarakat sesuai dengan ciri khasnya sebagai organisasi publik yaitu berorientasi pada pelayanan publik (service public oriented), bukan untuk mencari laba (profit oriented). Salah satu tantangan besar bagi organisasi publik saat ini adalah melaksanakan kinerja secara efektif dan efisien karena selama ini instansi pemerintahan diidentikkan dengan kinerja yang lambat, rumit, berbelit-belit, dan penuh dengan Korupsi, Kolusi, Nepotisme (KKN).

Berdasarkan UU Nomor 23 Tahun 2104 tentang Pemerintah Daerah, bahwa untuk penyelenggaraan pemeritahan daerah, kepala daerah perlu dibantu oleh perangkat daerah yang dapat menyelenggarakan seluruh urusan pemerintahan yang dilaksanakan oleh pemerintah daerah. Salah satu perangkat daerah dalam peraturan pemerintah ini adalah Kecamatan, yang merupakan wilayah kerja camat sebagai perangkat daerah kabupaten dan kota yang mempunyai tugas melaksanakan kewenangan pemerintahan yang dilimpahkan oleh bupati/walikota untuk menangani sebagian urusan otonomi daerah.

Kantor Kecamatan Dungingi Kota Gorontalo sebagai perangkat daerah yang mempunyai tugas pokok membantu pemerintah Kota Gorontalo dalam menyelenggarakan pemerintahan, pembangunan dan pembinaan kehidupan bermasyarakat serta melaksanakan sebagian kewenangan pemerintah Kota berdasarkan pelimpahan wewenang. Kantor Kecamatan Dungingi dituntut untuk dapat memberikan pelayanan yang berorientasi kepada kepuasan masyarakat.

Pengamatan peneliti bahwa kinerja yang rendah terlihat dari banyaknya tingkat kesalahan dan kerusakan yang dilakukan oleh pegawai, serta pegawai kurang cermat dalam melakukan tugastugasnya. Kemudian, pekerjaan yang seharusnya selesai hari ini itu diselesaikan esok harinya. Selain itu, seringnya terlambat masuk kantor dan rendahnya 
PUBLIK: Jurnal Manajemen Sumber Daya Manusia, Adminsitrasi dan Pelayanan Publik Sekolah Tinggi Ilmu Administrasi Bina Taruna Gorontalo Volume VII Nomor 12020

kehadiran karena banyak alasan, serta masih kurangnya kerjasama antar pegawai dalam melakukan pekerjaan.

Jika hal ini dibiarkan terus menerus, Kantor Kecamatan Dungingi yang mempunyai amanah untuk membantu tugas-tugas walikota tidak akan dapat melaksanakan tugasnya dengan baik. Oleh karena itu, Kantor Kecamatan Dungingi harus dapat membenahi permasalahan ini dengan cara memperhatikan nilai-nilai budaya organisasi publik yang berorientasi pada pelayanan publik (service public oriented), sehingga para pegawai mempunyai kesepahaman yang sama akan tujuan kerjanya.

Tujuan dari penelitian ini adalah untuk mengetahui pengaruh budaya organisasi $(\mathrm{X})$ yang terdiri dari budaya konstruktif $\left(\mathrm{X}_{1}\right)$, budaya pasif-defensif $\left(\mathrm{X}_{2}\right)$, dan budaya agresif-defensif $\left(\mathrm{X}_{3}\right)$ secara simultan serta secara parsial terhadap kinerja pegawai (Y) pada Kantor Camat Dungingi Kota Gorontalo.

\section{PERMASALAHAN}

Adapun rumusan dalam penelitian adalah bagaimana Pengaruh Budaya Organisasi Terhadap Kinerja Pegawai Di Kantor Camat Dungingi Kota Gorontalo?

\section{Tujuan Penelitian}

Berdasarkan Rumusan Masalah Tersebut, Maka Tujuan Penelitian Ini Adalah Untuk Mengetahui Dan Memberikan Gambaran Mengenai Pengaruh Budaya Organisasi Terhadap Kinerja Pegawai Di Kantor Camat Dungingi Kota Gorontalo

\section{Fokus Penelitian}

Berdasarkan latar belakang di tersebut, maka fokus penelitian adalah:

\section{Budaya Organisasi}

Yang dimaksud dengan budaya organisai adalah pola, keyakinan dan nilai-nilai yang seharusnya dianut.

\section{Budaya Pasif-Defensif}

Yang dimaksud dengan budaya pasifdefensif adalah Camat Dungingi harus memperhatikan budaya tersebut agar tidak terus berkembang yang dapat memberikan pengaruh terhadap kinerja pegawai.

\section{Ruang Interaksi}

Yang dimaksud denggan ruang interaksi adalah Camat harus lebih memberi ruang kepada pegawai berinteraksi dengan orang lain dengan cara yang tidak menantang keamanan mereka sendiri.

\section{METODE PENELITIAN}

Dalam melakukan penelitian ini peneliti memilih jenis penelitian survey dengan pendekatan kuantitatif, yaitu penelitian yang menggunakan kata-kata atau kalimat dan gambar serta angkaangka dengan memakai sampel dan menggunakan kuesioner sebagai alat pengumpulan data pokok.

Menurut Usman dan Akbar (2006:40) penelitian deskriptif dimaksud membuat penerimaan penyandaran secara sistematis, faktual, dan akurat mengenai fakta-fakta dan sifat-sifat tertentu.

Menurut Sugiyono (2008:8) metode penelitian kuantitatif dapat diartikan sebagai metode penelitian yang berlandaskan pada filsafat positivisme, digunakan untuk meneliti pada populasi 
PUBLIK: Jurnal Manajemen Sumber Daya Manusia, Adminsitrasi dan Pelayanan Publik Sekolah Tinggi Ilmu Administrasi Bina Taruna Gorontalo Volume VII Nomor 12020

atau sampel tertentu, pengumpulan data menggunakan instrumen penelitian, analisis data bersifat

\section{Teknik Pengumpulan Data}

Observasi, yakni kegiatan pengamatan terhadap budaya organisasi dan kinerja pegawai. Observasi atau pengamatan merupakan alat pelengkap di dalam penghimpunan data penelitian. Menurut Nisbet dan Watt (Sugiyono,2009:115) di dalam melakukan pengamatan harus menggunakan catatan tak berstruktur dalam tahap pertama yang terbuka, dalam tahap kedua memberikan perhatian pada sejumlah kategori terpilih.

Wawancara adalah suatu teknik pengumpulan informasi dengan tekhnik bertanya yang bebas, tetapi berdasarkan suatu pedoman (sesuai dengan ruang lingkup penelitian) guna mendapatkan informasi yang dibutuhkan. Wawancara ini mempergunakan pedoman wawancara berstruktur yakni menggunakan pedoman wawancara dimaksudkan untuk memperoleh informasi sebanyak mungkin mengenai permasalahan yang diamati. Kuesioner adalah teknik pengambilan data dengan membuat daftar pertanyaan yang diberikan pada anggota sampel yang bersedia memberikan respons (responden) atau jawaban.

\section{Metode Analisis Data}

Untuk memastikan sub-sub variabel apakah ada pengaruh fungsi kepemimpinan (X) yang tediri dari budaya konstruktif $\left(\mathrm{X}_{1}\right)$, budaya pasif- defensif $\left(\mathrm{X}_{2}\right)$, dan budaya agresif-defensif $\left(\mathrm{X}_{3}\right)$ terhadap kinerja pegawai (Y), maka pengujian dilakukan dengan uji analisis jalur (Path Analisys), dengan terlebih dahulu mengkonversi data skala ordinal ke skala interval melalui Method Successive Interval (MSI). Analisis jalur digunakan dengan pertimbangan bahwa pola hubungan antar variabel dalam penelitian adalah bersifat korelatif dan kausalitas. Data yang terkumpul dianalisis hubungan kausalnya antara subsub variabel yang dilakukan dengan menggunakan anlisis jalur (path analisys) yang memperlihatkan pengaruh. Gambar di atas juga memperlihatkan bahwa subsub variabel tersebut tidak hanya dipengaruhi oleh $\mathrm{X}_{1}, \mathrm{X}_{2}$, dan $\mathrm{X}_{3}$ tetapi ada variabel epselon $(\varepsilon)$ yaitu variabel yang tidak diukur dan diteliti.

\section{HASIL PENELITIAN DAN PEMBAHASAN}

Untuk mengetahui pengaruh budaya organisasi terhadap kinerja pelayanan publik Pada Kantor Camat Dungingi Kota Gorontalo, maka berikut ini akan dikemukakan analisis hasil statistik. Hasil analisis tersebut akan diketahui apakah variabel-variabel bebas (independen) memberikan pengaruh yang nyata (signifikan) terhadap variabel terikat (dependen). Hasil olahan data kerangka hubungan kausal antara $\mathrm{X}_{1}, \mathrm{X}_{2}$, dan $\mathrm{X}_{3}$ terhadap $\mathrm{Y}$ dapat dibuat melalui persamaan struktural sebagai berikut: $\mathbf{Y =}$ $0,445 X 1+0,332 \times 2+0,568 \times 3+0,435 \varepsilon$

Pengaruh budaya organisasi $(X)$ yang terdiri dari budaya konstruktif $\left(\mathrm{X}_{1}\right)$, 
PUBLIK: Jurnal Manajemen Sumber Daya Manusia, Adminsitrasi dan Pelayanan Publik Sekolah Tinggi Ilmu Administrasi Bina Taruna Gorontalo Volume VII Nomor 12020

budaya pasif-defensif $\left(\mathrm{X}_{2}\right)$, dan budaya agresif-defensif $\left(\mathrm{X}_{3}\right)$ secara simultan terhadap kinerja pelayanan publik (Y)

Hasil uji F Fitung menunjukkan hasil sebesar 14,745 sedangkan $F_{\text {tabel }}$ sebesar 2.880 dengan taraf signifikan adalah 0,000. Berdasarkan uji $\mathrm{F}$ tersebut menunjukkan bahwa $F_{\text {hitung }}>F_{\text {tabel }}$ $(14,745>2.880)$ dan tingkat signifikan sebesar $0,000<\alpha=0,05$. Ini berarti bahwa pada tingkat kepercayaan $95 \%$, secara statistik variabel budaya organisasi (X) yang terdiri dari budaya konstruktif (X1), budaya pasif-defensif (X2), dan budaya agresif-defensif (X3) secara simultan (bersama-sama) berpengaruh positif dan signifikan terhadap kinerja pegawai publik. Diterima.

Pengaruh Budaya Organisasi $(X)$ yang terdiri dari Budaya Konstruktif $\left(\mathrm{X}_{1}\right)$, Budaya Pasif-Defensif $\left(\mathbf{X}_{2}\right)$, dan Budaya Agresif-Defensif $\left(\mathbf{X}_{3}\right)$ Secara Parsial Terhadap Kinerja Pelayanan Publik (Y)

Hasil olahan data diperoleh bahwa budaya konstruktif $\left(\mathrm{X}_{1}\right)$ mempunyai nilai sig sebesar 0,007, kemudian dibandingkan dengan nilai probabilitas 0,05 ternyata nilai probabilitas 0,05 lebih besar dengan nilai probabilitas sig atau $(0,05>0,007)$ artinya signifikan. Jadi terbukti bahwa budaya konstruktif( $\left.\mathrm{X}_{1}\right)$ berpengaruh signifikan terhadap kinerja pegawai (Y). Diterima.

Hasil olahan data diperoleh bahwa budaya pasif-defensif $\left(\mathrm{X}_{2}\right)$ mempunyai nilai sig sebesar 0,017, kemudian dibandingkan dengan nilai probabilitas 0,05 ternyata nilai probabilitas 0,05 lebih besar dengan nilai probabilitas sig atau $(0,05>0,017)$ artinya signifikan. Jadi terbukti bahwa budaya pasif-defensif $\left(\mathrm{X}_{2}\right)$ berpengaruh signifikan terhadap kinerja pegawai (Y). Diterima.

Hasil olahan data diperoleh bahwa budaya agresif-defensif $\left(\mathrm{X}_{3}\right)$ mempunyai nilai sig sebesar 0,003, kemudian dibandingkan dengan nilai probabilitas 0,05 ternyata nilai probabilitas 0,05 lebih besar dengan nilai probabilitas sig atau $(0,05>0,003)$ artinya signifikan. Jadi terbukti bahwa budaya agresif-defensif $\left(\mathrm{X}_{3}\right)$ berpengaruh signifikan terhadap kinerja pegawai (Y). Diterima.

Temuan penelitian yang dapat dikemukakan adalah adanya pengaruh langsung positif dan signifikan secara simultan antara variabel budaya organisasi $(\mathrm{X})$ yang terdiri dari budaya konstruktif $\left(\mathrm{X}_{1}\right)$, budaya pasif-defensif $\left(\mathrm{X}_{2}\right)$, dan budaya agresif-defensif $\left(\mathrm{X}_{3}\right)$ terhadap variabel kinerja pegawai $(\mathrm{Y})$. Hasil uji persamaan struktural menunjukkan bahwa ketiga sub-variabel tersebut secara simultan berperan menjelaskan adanya makna pengaruh terhadap kinerja pelayanan. Besarnya pengaruh ketiga sub-variabel dari variabel budaya organisasi terhadap kinerja pelayanan publik sebesar 0,565 atau $56,5 \%$. Sedangkan variabel luar yang tidak dijelaskan dalam model 0,435 atau 43,5\%. Besarnya pengaruh ini menunjukkan bahwa semakin ditingkatkan budaya organisasi maka kinerja pegawai pada Kantor Camat Dungingi Kota Gorontalo semakin meningkat. 
Berdasarkan hasil penelitian menunjukkan adanya pengaruh positif dan signifikan budaya konstruktif $\left(\mathrm{X}_{1}\right)$ terhadap kinerja pegawai (Y) sebesar 0,445 atau $44,5 \%$ dengan nilai signifikansi sebesar 0,007. Hal ini menunjukkan bahwa semakin baiknya budaya konstruktif akan berdampak pada meningkatnya kinerja pegawai.

Berdasarkan hasil penelitian menunjukkan adanya pengaruh positif dan signifikan budaya pasif-defensif $\left(\mathrm{X}_{2}\right)$ terhadap kinerja pegawai (Y) sebesar 0,332 atau $33,2 \%$ dengan nilai signifikansi sebesar 0,017. Hal ini menunjukkan bahwa semakin baiknya budaya pasif-defensif akan berdampak pada meningkatnya kinerja pegawai.

Berdasarkan hasil penelitian menunjukkan adanya pengaruh positif dan signifikan budaya agresif-defensif $\left(\mathrm{X}_{3}\right)$ terhadap kinerja pegawai $(\mathrm{Y})$ sebesar 0,568 atau $56,8 \%$ dengan nilai signifikansi sebesar 0,003. Hal ini menunjukkan bahwa semakin baiknya budaya agresif-defensif akan berdampak pada meningkatnya kinerja pegawai.

Pelaksanaan pelayanan oleh pemerintah kepada masyarakat melibatkan kedua belah pihak untuk saling bekerjasama. Masyarakat diharapkan dapat berpartisipasi dalam upaya meningkatkan mutu pelayanan, yakni dengan memenuhi aturan dengan kesadaran dan menghargai administrator publik yang memberikan pelayanan. Suatu instansi pemerintah merasa dihargai dan akan bekerja dengan penuh tanggung jawab dalam memberikan pelayanan untuk memenuhi kebutuhan masyarakat.

Pelayanan publik yang dilakukan oleh pemerintah yang efektif dapat memperkuat demokrasi dan hak asasi manusia, mempromosikan kemakmuran ekonomi, kohesi sosial, mengurangi kemiskinan, meningkatkan perlindungan lingkungan, bijak dalam pemanfaatan sumberdaya alam, memperdalam kepercayaan pada pemerintahan dan administrasi publik.

Menurut Hanif Nurcholis, (2005:175-176) mengemukakan bahwa pelayanan publik adalah pelayanan yang diberikan oleh negara dan perusahaan milik negara kepada masyarakat untuk memenuhi kebutuhan dasarnya dalam rangka menciptakan kesejahteraan masyarakat. Pelayanan publik merupakan pelayanan yang diberikan untuk masyarakat banyak. Pelayanan publik diberikan oleh negara melalui organisasi atau perusahaan maupun instansi pemerintah demi menciptakan kesejahteraan masyarakat.

Secara alami budaya sukar dipahami, tidak berwujud, implisit dan dianggap biasa saja. Tetapi semua organisasi mengembangkan seperangkat inti pengandaian, pemahaman, dan aturan implisit yang mengatur perilaku seharihari dalam tempat kerja. Peran budaya dalam mempengaruhi perilaku karyawan semakin penting bagi organisasi.

Dengan dilebarkannya rentang kendali, didatarkannya struktur, diperkenalkannya tim-tim, dikuranginya formalisasi, dan diberdayakannya karyawan oleh organisasi, makna bersama 
PUBLIK: Jurnal Manajemen Sumber Daya Manusia, Adminsitrasi dan Pelayanan Publik Sekolah Tinggi Ilmu Administrasi Bina Taruna Gorontalo Volume VII Nomor 12020

yang diberikan oleh suatu budaya yang kuat memastikan bahwa semua karyawan diarahkan kearah yang sama. Pada akhirnya budaya merupakan perekat sosial yang membantu mempersatukan organisasi.

\section{SIMPULAN}

Berdasarkan hasil penelitian dan pembahasan dapat ditarik kesimpulan; Terdapat pengaruh budaya organisasi $(\mathrm{X})$ yang terdiri dari budaya konstruktif $\left(\mathrm{X}_{1}\right)$, budaya pasif-defensif $\left(\mathrm{X}_{2}\right)$, dan budaya agresif-defensif $\left(\mathrm{X}_{3}\right)$ secara simultan terhadap kinerja pegawai (Y) pada Kantor Camat Dungingi Kota Gorontalo serta terdapat pengaruh budaya organisasi $(\mathrm{X})$ yang terdiri dari budaya konstruktif $\left(\mathrm{X}_{1}\right)$, budaya pasif-defensif $\left(\mathrm{X}_{2}\right)$, dan budaya agresif-defensif $\left(\mathrm{X}_{3}\right)$ secara parsial terhadap kinerja pegawai (Y) pada Kantor Camat Dungingi Kota Gorontalo

\section{SARAN}

Berdasarkan kesimpulan yang telah diuraikan sebelumnya, maka saran dalam penelitian ini sebagai berikut; Sebaiknya Camat Dungingi lebih menerapkan budaya yang dalam organisasi. Karena dengan penerapan budaya organisasi, pola keyakinan dan nilai-nilai organisasi yang diyakini dan dijiwai oleh seluruh anggotanya dalam melakukan pekerjaan sebagai cara yang tepat untuk memahami, memikirkan, dan merasakan terhadap masalah-masalah terkait, sehingga akan menjadi sebuah nilai atau aturan di dalam organisasi menjadi pedoman dalam memberikan pelayanan yang baik kepada masyarakat; Kiranya Camat Dungingi lebih memperhatikan budaya pasifdefensif di Kantor Camat Dungingi, dimana memberikan pengaruh yang kecil terhadap kinerja pegawai. Camat harus lebih memberi ruang kepada pegawai berinteraksi dengan orang lain dengan cara yang tidak menantang keamanan mereka sendiri.

\section{DAFTAR PUSTAKA}

Achmad, Sobirin. 2007. Budaya Organisasi. Unit Penerbit Dan Percetakan Sekolah Tinggi Ilmu Manajemen YKPN.Yokyakarta.

Ardana, K.I., Mujiati N., Utama, M.W., 2012. Manajemen Sumber Daya Manusia. Cetakan Pertama. Yogyakarta: PT. Graha Ilmu.

Arikunto, Suharsimi. 2006. Prosedur Penelitian Suatu Pendekatan Praktik. Jakarta: Rineka Cipta.

Abdussamad, Juriko. 2019. Kualitas Pelayanan Publik di Kantor Dinas Kependudukan dan Catatan Sipil Kabupaten Gorontalo. PUBLIK: Jurnal Manajemen Sumber Daya Manusia, Administrasi dan Pelayanan Publik. Sekolah Tinggi Ilmu Administrasi Bina Taruna Gorontalo. Volume VI Nomor 2 Desember 2019. https://stiabinataruna.ejournal.id/PUBLIK/article/view/6

Dwiyanto, Agus. 2005. Mewujudkan Good Governance Melalui Pelayanan Publik. Yogyakarta: Gadjah Mada University Press. 
PUBLIK: Jurnal Manajemen Sumber Daya Manusia, Adminsitrasi dan Pelayanan Publik Sekolah Tinggi Ilmu Administrasi Bina Taruna Gorontalo Volume VII Nomor 12020

Hanif, Nurcholis. 2005. Teori dan Praktek Pemerintahan dan Otonomi Daerah. Jakarta: Grasindo.

Kurniawan, Najib. 2008. Paradigma Kebijakan Pelayanan Publik. In Trans. Malang

Mangkunegara, Anwar Prabu. 2001. Manajemen Sumber Daya Manusia Perusahaan. Bandung: Remaja Rosdakarya.

Mangkunegara. A, P. 2005. Sumber Daya Manusia Perusahaan. Bandung: Remaja Rosdakarya.

Moenir, A.S. 2002. Manajemen Pelayanan Umum di Indonesia. Jakarta: Bumi Aksara.

Notoatmodjo, $\quad$ Soekidjo. 2009. Pengembangan Sumber Daya Manusia. Jakarta: Rineka Cipta.

Nurmantu, Safri. 2007. Budaya Organisasi. Dari Chester I. Bernard ke Michael E. Porter. Jakarta: Midada Rahma Press.

Pasolong, Harbani. 2013. Kepemimpinan Birokrasi. Bandung: CV. Alfabeta.

Radiany, Rahmady. 2003. Pengaruh Budaya Organisasi Terhadap Kualitas Pelayanan Pada PTS Di Kalimantan Selatan. EKUITAS ISSN 1411-0393 Akreditasi No.49/DIKTI/Kep/2003.

Riduwan. 2008. Skala Pengukuran Variabel-variabel Penelitian. Bandung: Alfabeta.

Riani, Asri Laksmi. 2011. Budaya Organisasi. Cetakan Pertama, Edisi Pertama. Yogyakarta: Graha Ilmu.

Simanjuntak, Payaman J. 2005. Manajemen dan Evaluasi Kinerja. Jakarta: FE UI.
Sudarmanto. 2009. Kinerja dan Pengembangan Kompetensi SDM (Teori, Dimensi Pengukurandan Implementasi dalam Organisasi). Yogyakarta: Pustaka Pelajar.

Sugiyono. 2008. Metode Penelitian Kunatitatif Kualitatif dan $R \& D$. Bandung: Alfabeta.

Supartono. 2004. Ilmu Budaya Dasar, Bogor, Ghalia Indonesia. Usman dan Akbar. 2006. Pengantar Statistika”. Jakarta: Bumi Aksara.

Usman, Husaini dan Akbar, Purnomo Setiady. 2006. Pengantar Statistika. Jakarta: Bumi Aksara.

Wibowo. 2007. Manajemen Kinerja. Jakarta: Raja Grafindo Parsada. 